\title{
POLÍTICAS PÚBLICAS, TECNOLOGIAS EDUCACIONAIS E RECURSOS EDUCACIONAIS ABERTOS (REA)
}

\author{
POLÍTICAS PÚBLICAS, TECNOLOGÍAS Y RECURSOS EDUCACIONALES \\ ABIERTOS (REA)
PUBLIC POLICIES, EDUCATIONAL TECHNOLOGIES, AND OPEN EDUCATIONAL RESOURCES (REA)

\author{
Elena Maria MALLMANN ${ }^{1}$ \\ Daniele da Rocha SCHNEIDER ${ }^{2}$
}

RESUMO: A análise interpretativo-crítica centra-se nos microcontextos das políticas e práticas de formação de professores para aprimoramento da Fluência Tecnológico-Pedagógica (FTP) com Recursos Educacionais Abertos (REA). Nesse âmbito, os dispositivos das políticas públicas são analisados à luz de princípios universais como o direito à educação, democratização do conhecimento e aprendizagem ao longo da vida. A delimitação temática, os dados e as conclusões são sistematizadas sob a estrutura metodológica de três matrizes cartográficas típicas de uma pesquisa-ação: Matriz Dialógico-Problematizadora (MDP), Matriz Temático-Organizadora (MTO) e Matriz Temático-Analítica (MTA). Os resultados ressaltam a pluralidade de percepções, traduções e (re)interpretações locais das políticas relacionadas às tecnologias educacionais e Recursos Educacionais Abertos (REA). As práticas discursivas demarcam tipologias ingênuas em curvaturas que vão desde a negacionista até a futurologista. Como desfecho, a proposição afirmativa acentua a Fluência Tecnológico-Pedagógica (FTP) como princípio basilar para operar de modo crítico e emancipatório na interpretação, recontextualização e retemporalização das políticas públicas.

PALAVRAS-CHAVE: Políticas públicas. Tecnologias educacionais. Recursos Educacionais Abertos (REA). Formação de professores. Fluência Tecnológico-Pedagógica (FTP).

RESUMEN: El análisis interpretativo-crítica se centra en los microcontextos de las políticas y prácticas de formación del profesorado para mejoramiento de la Fluencia TecnológicoPedagógica (FTP) con Recursos Educacionales Abiertos (REA). En ese ámbito, los dispositivos de las políticas públicas son analizados a la luz de principios universales como el derecho a la educación, democratización del conocimiento y aprendizaje a lo largo de la vida. La delimitación temática, los datos y las conclusiones son sistematizadas bajo la estructura metodológica de tres matrices cartográficas típicas de una investigación-acción: Matriz Dialógico-Problematizadora (MDP), Matriz Temático-Organizadora (MTO) y Matriz Temático-Analítica (MTA). Los resultados señalan la pluralidad de percepciones, traducciones $y$ (re)interpretaciones locales de las políticas relacionadas a las tecnologías tipologías

\footnotetext{
1 Universidade Federal de Santa Maria (UFSM), Santa Maria - RS - Brasil. Professora-pesquisadora no Departamento Administração Escolar. Doutorado em Educação (UFSC). ORCID: https://orcid.org/0000-00027611-3904. E-mail: elena.ufsm@gmail.com

${ }^{2}$ Universidade Federal de Santa Maria (UFSM), Santa Maria - RS - Brasil. Pós-Doutoranda no Programa de PósGraduação em Educação. ORCID: https://orcid.org/0000-0003-4823-8133. E-mail: dani.qmc@gmail.com
} 
ingenuas en curvaturas que van desde la negacionista hasta la futorologista. Como desfecho, la proposición afirmativa acentúa la Fluencia Tecnológico-Pedagógica (FTP) como principio basilar para operar de modo crítico y emancipador en la interpretación, recontextualización y retemporalización de las politicas públicas.

PALABRAS CLAVE: Políticas públicas. Tecnologías educacionales. Recursos Educacionales Abiertos (REA). Formación del profesorado. Fluencia Tecnológica-Pedagógica (FTP).

ABSTRACT: The interpretive-critical analysis focuses on the micro-contexts of teacher training policies and practices for enhancing Technological-Pedagogical Fluency (FTP) with Open Educational Resources (REA). Within this framework, public policy devices are analyzed in light of universal principles such as the right to education, democratization of knowledge, and lifelong learning. The thematic delimitation, the data and the conclusions are systematized under the methodological structure of three cartographic matrices typical of an actionresearch: Dialogic-Problematizing Matrix (MDP), Thematic-Organizing Matrix (MTO) and Thematic-Analytical Matrix (MTA). The results highlight the plurality of local perceptions, translations, and (re)interpretations of policies related to educational technologies and Open Educational Resources (REA). The discursive practices demarcate naive typologies in curvatures ranging from denialist to futurologist. As an outcome, the affirmative proposition emphasizes Technological-Pedagogical Fluency (FTP) as a basic principle to operate in a critical and emancipatory way in the interpretation, recontextualization and retemporalization of public policies.

KEYWORDS: Public policies. Educational technologies. Open Educational Resources (REA). Teacher education. Technological-Pedagogical Fluency (FTP).

\section{Introdução}

Os microcontextos da formação e performance docente são nutridos pelas orientações perspectivadas nas políticas públicas educacionais vigentes. Parte-se do princípio de que em sociedades com formas de governo democráticas, as políticas públicas são a possibilidade de materializar os ideários éticos do bem comum e preconizar o exercício da cidadania sob o pressuposto da igualdade de todas as pessoas. Tendo em vista a soberania do povo, mediada pelas metodologias recorrentes em democracias representativas, as políticas públicas implicam decisões orientadas para a vida em comunidade e, por isso, impactam todos os indivíduos e coletividades. Políticas públicas são baseadas em regras e acordos nacionais, normalmente expressos em documentos magnos, como é o caso da Constituição Federal. No campo da educação, no patamar macro figuram a Lei de Diretrizes e Bases da Educação Nacional (LDB), bem como o Plano Nacional de Educação (PNE).

Nesse texto, a problematização dos dispositivos legais tem como propósito a construção de uma análise interpretativo-crítica a respeito dos microcontextos das políticas e práticas de 
formação de professores para aprimoramento da Fluência Tecnológico-Pedagógica (FTP) com Recursos Educacionais Abertos (REA).

Destarte, o artigo está estruturalmente organizado em cinco seções. Na primeira seção trata-se da interface entre políticas públicas e tecnologias educacionais, tendo em vista os aportes conceituais da democracia, ética e formação cidadã com foco nos textos da legislação vigente. Na segunda parte, desdobra-se características e particularidades dos Recursos Educacionais Abertos (REA) atrelados aos princípios basilares da Fluência TecnológicoPedagógica consoante ao percurso da primeira parte. No terceiro momento apresenta-se a sistemática dos processos metodológicos da tipologia da pesquisa-ação aparelhada pelas três matrizes cartográficas: Matriz Dialógico-Problematizadora (MDP), Matriz TemáticoOrganizadora (MTO) e Matriz Temático-Analítica (MTA). Nessa esteira, na quarta seção são compostos os resultados e discussões. Conclusivamente, no quinto momento, frisa-se as considerações finais.

\section{Políticas Públicas e Tecnologias Educacionais}

O processo político é permeado pelas tensões dos macro e microcontextos que originam e, ao mesmo tempo, são o palco de confronto dos dispositivos textuais da legislação vigente. Desse modo, os movimentos de transposição das políticas públicas para os microcontextos pedagógicos condensam esses tensionamentos nem sempre totalmente pacificados no texto da lei. Ao mesmo tempo, geram ondas discursivas, sonoridades éticas, análises empíricas e modelos teóricos com potencial para reformulação dos dispositivos legais. Os movimentos das políticas públicas são históricos, processuais, ascendentes, abarcando convergências e dissonâncias que colocam em xeque as demandas sociais e os interesses de quem detém o poder.

Desse modo, a reflexão tem como parâmetro os princípios universais do direito à educação, da democratização do conhecimento e da aprendizagem ao longo da vida. Como expressa Wencznovicz (2020, p. 1751):

A educação é um direito humano e aponta para um horizonte de conquistas. A educação como Direito Humano, ou direitos que valem para todos, surge para as sociedades entenderem a irracionalidade que é a banalização da vida, sendo que o êxito nos enfrentamentos dos problemas advém do pensar, do teorizar, de esclarecer os fatos e reconhecer as coletividades como portadores de direitos.

Portanto, é preciso, com urgência, discutir o papel das políticas públicas no amparo, fomento e mobilização das performances docente e discente mediadas por tecnologias 
educacionais em rede. Isso situa-se no amplo espectro da valorização do processo de construção do conhecimento como racionalidade interpretativo-crítica. Desse modo, a tese é que o caminho para ampliação e consolidação da educação mediada por tecnologias educacionais em rede, especialmente os REA, é compreender o caráter mobilizador das políticas públicas educacionais. Com isso, pretende-se esclarecer que os textos da legislação vigente admitem uma natureza diretiva principalmente nas instituições públicas. Isso fica evidente diante dos preceitos constitucionais que regem a atuação do servidor na administração pública em todas as esferas de Governo (Federal, Estadual, Distrital e Municipal). Nessa linha de raciocínio, colabora o entendimento de Guerra; Figueiredo e Zanardini (2020, p. 2200), ao frisarem os conceitos do campo do direito vinculados às políticas públicas:

[...] as Políticas Públicas vinculam-se ao campo do Direito, notadamente do Direito Constitucional, a partir dos conceitos de controle concentrado da constitucionalidade; da inconstitucionalidade; e da judicialização das Políticas Públicas, bem como sobre as diferenças entre a concepção de Educação como serviço público, bem público e direito público.

Os ditames constitucionais da administração pública estão expressos no Art. 37 da Constituição Federal: a) legalidade: é determinante cumprir o que está previsto na legislação; b) impessoalidade: as decisões devem ser pautadas na noção de neutralidade, já que não se deve dar tratamento preferencial a qualquer pessoa, física ou jurídica; c) publicidade: todas as ações devem ser de conhecimento público com base na transparência; d) eficiência: as ações praticadas pelo serviço público são regidas pela ideia de utilidade, racionalidade e economicidade no uso dos meios, visando atingir os melhores resultados; e) moralidade administrativa: conduta baseada no conjunto de regramentos éticos e de honestidade que configuram o código da administração pública; f) probidade administrativa: acentua decisões e ações do servidor que não causem prejuízos, não gerem enriquecimento ilícito e/ou utilização de informações de maneira privilegiada; g) iniciativa popular: monitoramento e ações populares

Esses princípios constitucionais tornam evidente que nas formas de governo e gestão em democracias representativas, as políticas públicas, materializadas na legislação vigente, são núcleos orientadores das decisões e ações no campo perene de resolução de conflitos. Ou seja, nas tensões entre as demandas sociais e o Estado. Nesse ínterim, cabe explicitar que esse entendimento sobre o papel e poder orientador dos dispositivos legais não pode ter como essencialidade um fundamento instrumental e aplicativo. Políticas públicas em sociedades democráticas não podem ser estruturas de ordem jurídica tramadas por entidades 
governamentais dirigidas acriticamente à um público específico que as administra, monitora, avalia e regula. De acordo com Mainardes (2006), devido às políticas públicas serem um campo de controvérsias existe a "necessidade de se articularem os processos macro e micro na análise de políticas educacionais", tendo em vista os "processos micropolíticos e a ação dos profissionais que lidam com as políticas no nível local" (MAINARDES, 2006, p. 49). Nessa linha analítica, Wencznovicz (2020, p. 1754-1755) afirma que a educação, "quando disseminada de forma universal pode ser um relevante mecanismo para a promoção de oportunidades para a coletividade".

O alcance pleno de princípios universais como o direito à educação, à democratização do conhecimento e à aprendizagem ao longo da vida exige muito mais do que o trabalho restritivo das legiões de guardiões dos documentos legais. O trabalho dos gestores e especialistas precisa ser problematizado, especialmente quando esses grupos produzem o suporte para a continuidade dos mecanismos repressivos, da limitação ao acesso, das estruturas precárias de trabalho dos profissionais da educação, da desvalorização do conhecimento criado nos microcontextos emergentes.

Nesse sentido, no contorno dos processos formativos, com destaque para o papel das universidades, Santana, Cardoso e Silva (2019, p. 2005) afirmam que a formação universidade universitária tem sido pautada por uma "racionalidade técnica". Quando o pensamento se comporta com linearidade em relação ao papel das políticas públicas, um amplo volume de informações especializadas é produzido a respeito da educação, mas com viés altamente reprodutivo e mantenedor dos grupos detentores do poder.

No campo das tecnologias educacionais, os discursos mais comuns que circulam entre a comunidade são os dados referentes à falta de condições e infraestrutura. Nessa perspectiva, consumidores desavisados assumem e favorecem as posições ingênuas que maculam o potencial interativo, colaborativo e humanizador da educação mediada pelas tecnologias. Oportuno ressaltar que a universalidade do direito à educação, da democratização do conhecimento e da aprendizagem ao longo da vida perpassam pelo acesso e a participação ativa, coprodutora da vida mediada pelas tecnologias. Segundo Vieira Pinto (2005, p. 308), "o homem nunca se livra da tecnologia, apenas transforma sua relação com a existente, substituindo-a por outra melhor, mais produtiva e econômica".

Nessa perspectiva, o autor ressalta o papel do conhecimento científico, que, conforme as inferências interpretativo-críticas produzidas, é incentivado, intensificado e completamente assentado em políticas públicas. Nessa visão de mundo, ciência, tecnologia e sociedade estão sempre integradas. Ou seja, política pública não é algum tipo de ação ou programa que supõe 
como destino determinados grupos sociais mais ou menos favorecidos em termos de acesso à cultura, saúde, educação, bem estar social, etc. Nesse ponto é crucial a contribuição de Viera Pinto (2005, p. 250-251) quando diz que a:

[...] mentalidade ingênua pensa que governar é sinônimo de administrar. Governar consiste em instituir o sistema de convivência humana. Em tal sentido designa um ato de ordem existencial, exigindo portanto outra forma de pensar, configurado nas categorias da lógica dialética. [...] Governar identifica-se ao estabelecimento do sistema de relações sociais e não simplesmente à tomada de iniciativas de progresso material, sem compreender o que significam na reciprocidade estabelecida com as condições existenciais de vida do povo.

Nessa linha, cumpre explicitar que as políticas públicas são mecanismos efetivos para estabelecer, organizar, monitorar, regular o sistema completo de relações sociais, independente da forma de governo. Ao considerar a legislação vigente, as ações e programas como dispositivos que dão materialidade e visibilidade às políticas públicas, torna-se oportuno compreender que os impactos na realidade social, política e econômica ocorrem em todas as instâncias da vida humana. Inclusive, estendem-se para além das demarcações geográficas. Por isso, mesmo os microcontextos são complexidades determinantes e determinadas pelos mecanismos e movimentos internacionais. Assim, o espectro analítico nesse momento são os REA e a Fluência Tecnológico-Pedagógica (FTP) requerida para o alcance dos direitos fundamentais.

\section{Recursos Educacionais Abertos (REA) e Fluência Tecnológico-Pedagógica (FTP)}

As políticas são sempre dinâmicas em virtude das demandas sociais que não são fixas, especialmente porque muitas delas nunca se consolidaram ao longo da história. O que dá vida às políticas públicas é a efetiva dinâmica de compreensão e transposição nos microcontextos ao que está textualmente estabelecido na legislação vigente, no que tange à pesquisa, docência, recursos, financiamento, gestão, avaliação e regulação.

As interferências e influências, inclusive dos mecanismos internacionais, compilam um universo de princípios constitutivos das políticas públicas educacionais cujas análises possuem tantas variantes quanto o quanti-qualitativo do conhecimento produzido. Assim, é preciso ter claro que a educação aberta é um movimento global que encontra subsídios operacionais nas práticas abertas e fomento operacional nos REA. A Organização das Nações Unidas para a Educação, a Ciência e Cultura (UNESCO) é considerada precursora na coordenação, divulgação e elaboração de documentos internacionais com definições e diretrizes sobre os 
REA.

O cenário que origina os REA é conhecido como o movimento educação aberta, que emerge tanto da tradição educativa de partilha de boas ideias entre professores e estudantes, quanto da cultura de integração das tecnologias educacionais em rede, com os princípios da colaboração através da coautoria. Esse movimento pauta-se na premissa de que professores e estudantes devem ter a liberdade de usar, personalizar, contextualizar, melhorar e redistribuir os recursos educacionais, sem restrições. Nesse sentido, possibilitando abertura para além do acesso, potencializa não somente difusão de conhecimento, mas viabilidade para sua aplicação em ações interventivas, nos diferentes contextos e setores educacionais emergentes ou consolidados (JACQUES; MALLMANN; BAGETTI, 2019, p. 1046).

De acordo com as autoras, REA mobilizam a produção de conhecimento científico, cultural, educacional, especialmente por promover processos de partilha, autoria e coautoria. A prática das cinco liberdades dos REA, os chamados 5R cunhados por Willey (2014), que são reter, reutilizar, revisar, remixar, redistribuir, são a base dos processos de transposição didática para recontextualizar e retemporalizar materiais de ensino, aprendizagem e pesquisa. Trata-se, portanto, de uma cultura voltada para a mobilização do conhecimento como resolução de conflitos, resolução de problemas, melhoria das condições de vida e bem-estar. Ou seja, um senso ético exatamente alinhado com os mais puros fundamentos democráticos das políticas públicas.

O ano de 2002 é referência no histórico dos REA, sendo o Fórum sobre o impacto de Softwares Didáticos Abertos no Ensino Superior nos países em desenvolvimento o lócus que gerou a primeira menção aos REA. Dez anos mais tarde, novamente sob a coordenação da UNESCO, foi realizado em Paris o Congresso Mundial sobre Recursos Educacionais Abertos (REA). No documento Declaração REA de Paris, o conceito REA está sistematizado como:

[...] materiais de ensino, aprendizagem e investigação em quaisquer suportes, digitais ou outros, que se situem no domínio público ou que tenham sido divulgados sob licença aberta que permite acesso, uso, adaptação e redistribuição gratuitos por terceiros, mediante nenhuma restrição ou poucas restrições. O licenciamento aberto é construído no âmbito da estrutura existente dos direitos de propriedade intelectual, tais como se encontram definidos por convenções internacionais pertinentes, e respeita a autoria da obra (UNESCO, 2012, p. 1).

Esse documento de 2012 sistematiza todo um percurso de eventos e atividades de diversos grupos que evidentemente influenciam a formulação dos textos legais das mais diversas nações. Nessa variante, é preciso levar em consideração que REA não é um conceito aleatório e isolado de todo um percurso histórico de trabalho mediado por tecnologias 
educacionais, mas é ética de inclusão. Na década de 1990, precursores dos REA foram os Objetos de Aprendizagem (WILEY, 2000), que, com o advento dos conteúdos digitais, já contemplavam uma estrutura organizativa em torno dos currículos. $\mathrm{O}$ design e empacotamento de documentos digitais foi acentuado com a promulgação dos conteúdos em formatos interoperáveis na web, possibilidades de repositórios acessíveis, ampliação da oferta de cursos a distância com suporte de ferramentas para interação na Internet. Assim, no início dos anos 2000, a granularização dos conteúdos digitais, a interatividade e seu potencial para reutilização em diferentes microcontextos já era um potencial presente nos Objetos de Aprendizagem.

Ao que se pergunte sobre o que há de novo e original nos REA em comparação às possibilidades técnicas anteriores, a resposta é certeira: REA nasceram com um propósito humanitário, inclusivo e equitativo oxigenado. A análise interpretativo-crítica em torno dos assentamentos jurídicos, tecnológicos e pedagógicos dos REA não é um exercício de advocacia que desconhece os conflitos, os desafios, os confrontos comerciais, a precarização do trabalho docente, as facetas da formação docente, o desinvestimento do Estado no financiamento público da educação.

Ou seja, enquanto os Objetos de Aprendizagem se fixavam na possibilidade de distribuição e reúso, os REA adotam uma perspectiva de cocriação como possibilidade de transformação conforme as particularidades de cada microcontexto. Sobre a liberdade de escolha e a participação soberana dos profissionais da educação na escolha dos recursos educacionais, Viera Pinto (2005, p. 257) destaca que "o poder de decisão na escolha, manutenção e direção da tecnologia, não só quanto à origem mas igualmente quanto à natureza dela, constitui o traço mais significativo para comprovar a posse da autoconsciência”. Como movimento político centrado na prática das cinco liberdades, os REA e todas as práticas abertas adquirem uma amplitude democrática porque permitem e incentivam a participação livre. Essa participação entendida não apenas como acesso, mas como codesenvolvimento na medida em que se constrói, do ponto de vista epistemológico, uma racionalidade crítica e emancipatória. A prática das cinco liberdades que fundamenta os REA fomenta a construção de Fluência Tecnológico-Pedagógica (FTP) em movimentos de coautoria nas soluções tecnológicoeducacionais. Soluções essas que se inserem no processo político de resolução dos problemas mais prementes de acordo com as transposições requeridas para recontextualização, retemporalização e recompilação conceitual em virtude das diretrizes curriculares, metas avaliativas, configurações logísticas, valorização dos profissionais da educação, pluralismo de ideias e concepções pedagógicas.

Nesse sentido, em relação aos REA é imprescindível que as políticas públicas, 
concretizadas pela legislação vigente, demarquem o papel insubstituível do Estado articulado com o poder soberano da sociedade civil. O avanço das políticas sociais neoliberais e perspectivas gerencialistas na educação, denunciadas por Apple (2002), não pode descaracterizar o movimento dos REA como possibilidade real de assegurar direito à educação, democratização do conhecimento e aprendizagem ao longo da vida. Investir no desenvolvimento e aprimoramento da FTP dos profissionais da educação em torno das tecnologias e dos REA é contribuir no fortalecimento da prática da liberdade de escolha e expressão do pensamento, da autonomia didático-pedagógica, da pluralidade, conforme determinam os princípios constitucionais. Segundo Apple (2002, p. 56), “a educação é um espaço de conflitos e compromissos [...]. Desse modo, a educação é simultaneamente causa e efeito, ou seja, determinada e determinante".

$\mathrm{O}$ argumento em torno da FTP adquire força ao se considerar que as políticas públicas educacionais são aportes imprescindíveis para alavancar a educação mediada por tecnologias educacionais em rede nesse "espaço de conflitos e compromissos". Desenvolver e aprimorar FTP é um processo contínuo que perdura ao logo de toda a vida. É com mais e melhor FTP que os profissionais da educação podem dirimir os antagonismos e discrepâncias das políticas públicas educacionais quando se trata das tecnologias educacionais e, invariavelmente, dos REA.

FTP é calcada em saberes tanto de ordem teórica quanto prática e emancipatória. O processo de resolução de problemas educacionais, como processo essencialmente político, implica racionalidade materializada em torno da tecnologia e da pedagogia. "Para tanto, argumenta-se que as dimensões do empowerment, da criatividade, inventividade e participação democrática na produção do conhecimento científico-tecnológico, potencializadas pela cultura digital, precisam ser contempladas na formação universitária” (MALLMANN; QUINTASMENDES, 2020, p. 225).

A fluência requerida nos microcontextos do acoplamento tecnológico-pedagógico tem sempre um caráter técnico, prático e emancipatório que implica habilidades contemporâneas, conceitos fundamentais e capacidades intelectuais. Criar, inventar, participar da vida política mediada pelas interações e interatividade tecnológica da vida contemporânea implica saber transitar com fluência entre os macro e microcontextos pessoais, coletivos, profissionais.

No quadro funcional da FTP que não se restringe ao universo digital, as habilidades contemporâneas explicitam os saberes técnicos da atividade humana, que é interventiva como modo de produção da existência. Ou seja, são saberes repetitivos (por exemplo ligar/desligar, conectar cabos, preencher login e senhas, digitar/apagar/corrigir, copiar/colar. etc) até que 
novos procedimentos técnicos sejam criados e/ou os antigos melhorados. Os conceitos fundamentais dão conta da natureza prática e convém explicar que se trata das operações necessárias para criar soluções baseadas nos saberes técnicos para contextos, situações e finalidades particulares. Trata-se de ações informadas pela composição teoria-prática ou viceversa. Sem esse componente prático da FTP, a transposição das políticas públicas nos microcontextos pedagógicos ficaria inviabilizada como atividade humana interpretativo-crítica.

Os saberes técnicos e práticos descontextualizados localmente dos saberes culturais, crenças, valores e infraestrutura figuram isolados, ou seja, remetem aos modelos reprodutivos típicos de uma cultura e uma vertente política persuasiva, colonialista, neoliberal e neoconservadora. Isso quer dizer que níveis muito baixos de FTP comprometem a potencialidade das tecnologias educacionais e dos REA nos microcontextos, mesmo que haja previsão nos dispositivos da legislação vigente.

Já no patamar da cultura da produção da mudança embasada na ética democrática, na equidade, inclusão e pluralidade, a FTP é exigente. Não contente com o saber fazer de ordem técnica e prática e impele para um conhecimento emancipatório assentado em capacidades intelectuais. Pode ser entendido como uma terceira dimensão da FTP, mas de modo algum está desconexo das duas dimensões anteriores. Produzir e compartilhar conhecimentos, conteúdos, soluções em comunidades em macro e microcontextos é um processo formativo e (auto)reflexivo contínuo. Assim, é uma capacidade intelectual que precisa da tutela das políticas públicas materializadas na legislação vigente. Com as bases no caráter emancipatório, a acepção da FTP em torno das tecnologias, em especial dos REA, é coerente com a ética democrática do direito universal à educação, do conhecimento para todos e da aprendizagem ao longo da vida.

\section{Processos metodológicos}

As pesquisas têm analisado as possibilidades e os desafios no que se refere à integração de Recursos Educacionais Abertos (REA) em microcontextos de formação inicial e continuada de professores. A pesquisa-ação tem produzido dados em cursos de licenciatura, mestrado, doutorado e em programas de formação continuada de professores da educação básica e da educação superior. Inicialmente, esses programas eram direcionados aos profissionais do Rio Grande do Sul, mas, no momento, sob demanda, já tem sido ampliado mediante acordos de cooperação técnica com instituições de outros estados da federação.

É desse modo que essas ações de pesquisa-ação reúnem as evidências dos microcontextos com intencionalidade direcionada para a resolução dos problemas mais 
urgentes. Evidentemente, isso está articulado com os princípios universais que premeditam a educação em diversas modalidades e formatos com vistas à ampliação de vagas, inclusão de mais pessoas, acessibilidade, respeito à diversidade e às diferenças, interiorização e expansão da educação pública etc.

Os princípios teóricos da pesquisa-ação são confluentes com os cânones da educação aberta, dos REA e da FTP. Isso porque assentam-se na participação de todos os envolvidos no exame crítico da prática, a construção coletiva de soluções para os problemas mais prementes, a perspectiva colaborativa para melhoria das condições de trabalho, de vida, desenvolvimento profissional. Kemmis e Mctaggart (1988) e Elliot (1997), autores referência em pesquisa-ação de matriz emancipatória, ressaltam essa produção de conhecimentos visando melhorias individuais e coletivas.

Para tanto, a delimitação temática, os dados e as conclusões são sistematizadas sob a estrutura metodológica de três matrizes cartográficas típicas de uma pesquisa-ação: Matriz Dialógico-Problematizadora (MDP), Matriz Temático-Organizadora (MTO) e Matriz Temático-Analítica (MTA). Essa trilogia cartográfica pública no texto de Mallmann (2015) tem o propósito de contemplar o percurso cíclico na dinâmica processual da pesquisa-ação desdobrada nas etapas de (re)planejamento, ação, observação e reflexão. A sistemática processual da pesquisa-ação com foco nas tecnologias educacionais, especialmente os REA, tem como característica particular a amplitude de dados. Assim, as fases da delimitação temática, produção e análise interpretativo-crítica dos resultados e a construção de proposições teóricas tem sido pautadas pelas MDP, MTO e MTA.

A MDP tem como principal propósito organizar a delimitação do tema de pesquisa e, completa, resulta em dezesseis células de questionamentos. Para o desenho da MDP inicia-se pela definições de cada elemento da matriz, que nesse caso são: Temática -> inovação didáticometodológica mediada por tecnologias educacionais hipermídia, especialmente Recursos Educacionais Abertos (REA); Professores -> professores da Educação Básica (EB) e da Educação Superior (ES) em cursos de formação inicial e continuada de professores; Estudantes -> da Educação Básica (EB) das escolas envolvidas, licenciandos, mestrandos e doutorandos; Contexto $->$ diretrizes das políticas públicas educacionais para integração de tecnologias na Educação Básica e na Educação Superior. No Quadro 1, destaque para as células da MDP que tem como foco o contexto, mescladas com os demais elementos. 
Quadro 1 - Recorte da Matriz Dialógico-Problematizadora (MDP)

\begin{tabular}{|c|c|c|c|c|}
\hline & 1 -Professores & 2 - Estudantes & 3- Temática & 4- Contexto \\
\hline $\begin{array}{l}\text { D } \\
- \\
\text { C } \\
\text { on } \\
\text { te } \\
\text { xt } \\
\text { o }\end{array}$ & $\begin{array}{l}\text { D1) As políticas } \\
\text { públicas estabelecem } \\
\text { diretrizes claras para } \\
\text { que os professores } \\
\text { possam planejar, } \\
\text { produzir, reutilizar e } \\
\text { recompartilhar recursos } \\
\text { que permitam } \\
\text { aprofundar e consolidar } \\
\text { conhecimentos por } \\
\text { meio da integração das } \\
\text { tecnologias } \\
\text { educacionais } \\
\text { hipermídia, } \\
\text { especialmente } \\
\text { Recursos Educacionais } \\
\text { Abertos (REA)? }\end{array}$ & $\begin{array}{l}\text { D2) As políticas } \\
\text { públicas estabelecem } \\
\text { diretrizes claras para } \\
\text { que os estudantes } \\
\text { possam aprofundar e } \\
\text { consolidar } \\
\text { conhecimentos por meio } \\
\text { da integração das } \\
\text { tecnologias } \\
\text { educacionais } \\
\text { hipermídia, } \\
\text { especialmente } \\
\text { Recursos Educacionais } \\
\text { Abertos (REA)? }\end{array}$ & $\begin{array}{l}\text { D3) A implementação } \\
\text { de cursos de formação } \\
\text { continuada para } \\
\text { professores no formato } \\
\text { Small Open Online } \\
\text { Courses (SOOC) } \\
\text { potencializa inovação } \\
\text { didático-metodológica } \\
\text { e curricular na EB? }\end{array}$ & $\begin{array}{l}\text { D4) As políticas } \\
\text { públicas educacionais } \\
\text { vigentes estabelecem } \\
\text { diretrizes claras para } \\
\text { introduzir, aprofundar e } \\
\text { consolidar a integração } \\
\text { das tecnologias } \\
\text { educacionais } \\
\text { hipermídia, } \\
\text { especialmente os } \\
\text { Recursos Educacionais } \\
\text { Abertos (REA) na EB? }\end{array}$ \\
\hline
\end{tabular}

Fonte: Elaboração própria

Nessa linha (auto)reflexiva, engajar-se no movimento REA pode ser um caminho viável para melhoria das práticas nos microcontextos. Ampliar condições para a conscientização crítica a respeito da educação como processo histórico, social e cultural é fundamental para compreender as relações entre ciência, tecnologia e sociedade. Do mesmo modo, vivenciar democraticamente os espaços-tempos das políticas públicas que determinam e são determinadas tanto pelo macro quanto pelos microcontextos.

Para elaboração, implementação e avaliação recorrente da pesquisa-ação em etapas cíclicas de planejamento, ação, observação e reflexão (avaliação e deliberação) inicia-se pela delimitação conceitual da preocupação temática. Isso é primordial para evidência e caracterização do problema central que circunda tanto o objetivo geral quanto os específicos. Assim, cada questão de pesquisa somente adquire potencial operacional quando é possível sinalizar os respectivos desdobramentos metodológicos para alcance das metas embutidas. Cada célula da matriz contém uma única questão que é considerada a síntese após a depuração dialógica com todos os envolvidos. Nas fases em que ainda pulsam mais questões, indica-se que sejam realizadas mais etapas (auto)reflexivas para reconhecimento do que é considerado mais problemático e passível de investigação crítica com fins de resolução.

Para responder as questões, o movimento prospectivo e retrospectivo da pesquisa-ação comporta várias possibilidades de produção de dados, como observação participante, questionários tipo survey, análise de documentos, registros das participações nos ambientes online etc. São justamente as informações oriundas desses procedimentos metodológicos que são dispostas na MTO e alimentam as análises para composição das assertivas finais na MTA. 


\section{Resultados e discussões}

O recorte analítico são as células D1, D2, D3 e D4 porque referem preocupações temáticas explícitas em relação ao conjunto de políticas públicas. Para essas quatro células, os indicativos de origem da produção dos dados são compilados na MTO, sendo oriundos, nesse caso, de seminários temáticos na pós-graduação 2019/2020; componentes curriculares nas licenciaturas 2018/2019/2020; edições 2018/2019/2020 de cursos de formação continuada para rede pública. Nesse esboço cartográfico sobre as tecnologias e os REA nas políticas públicas nacionais e documentos internacionais, foram produzidas sínteses ilustradas em forma de redes temáticas (Figuras 1, 2 e 3).

Figura 1 - Dispositivos legais UNESCO, CNE, Portaria n. 451

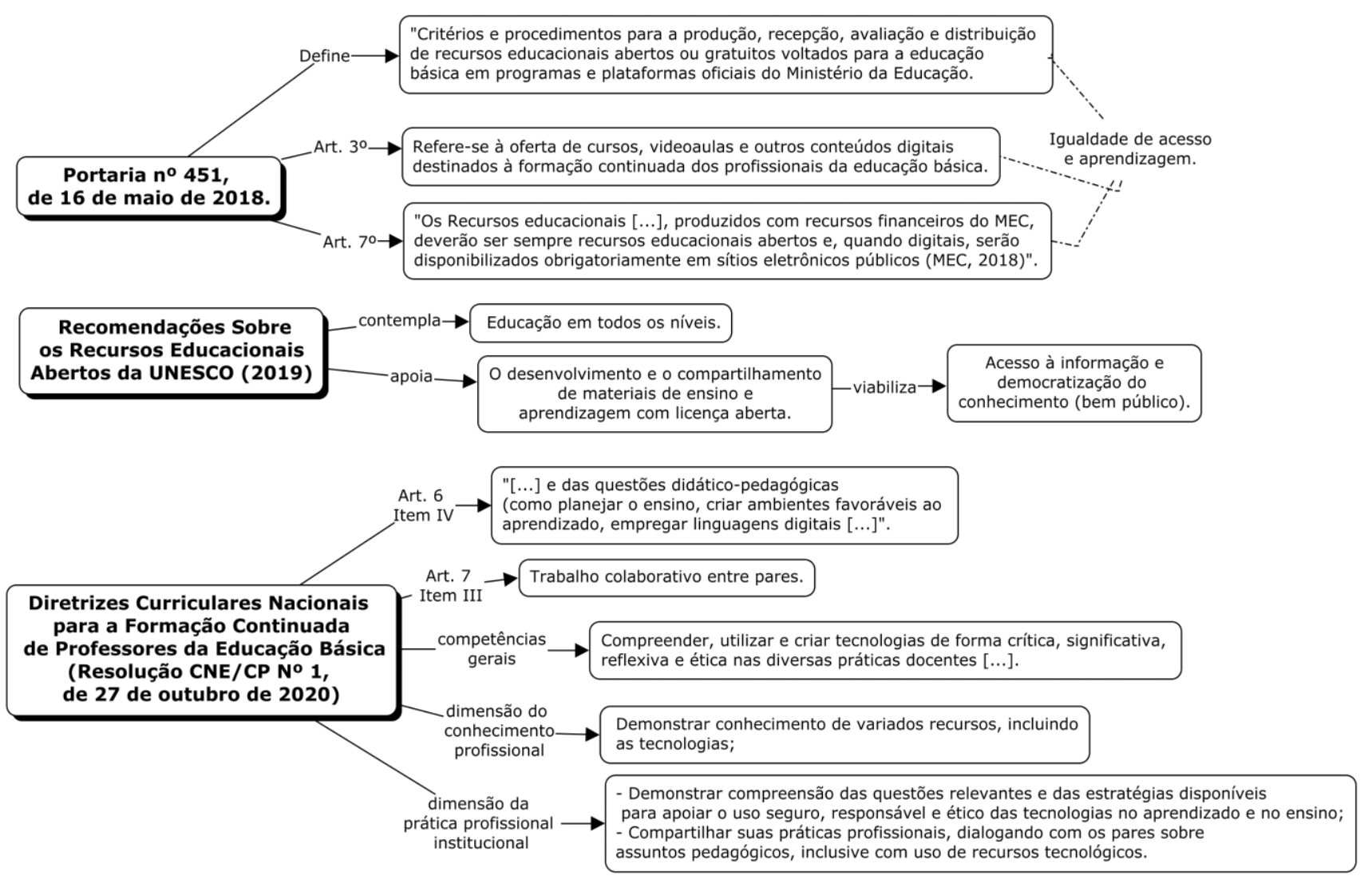

Fonte: Elaboração própria 
Figura 2 - Dispositivos legais do PNE

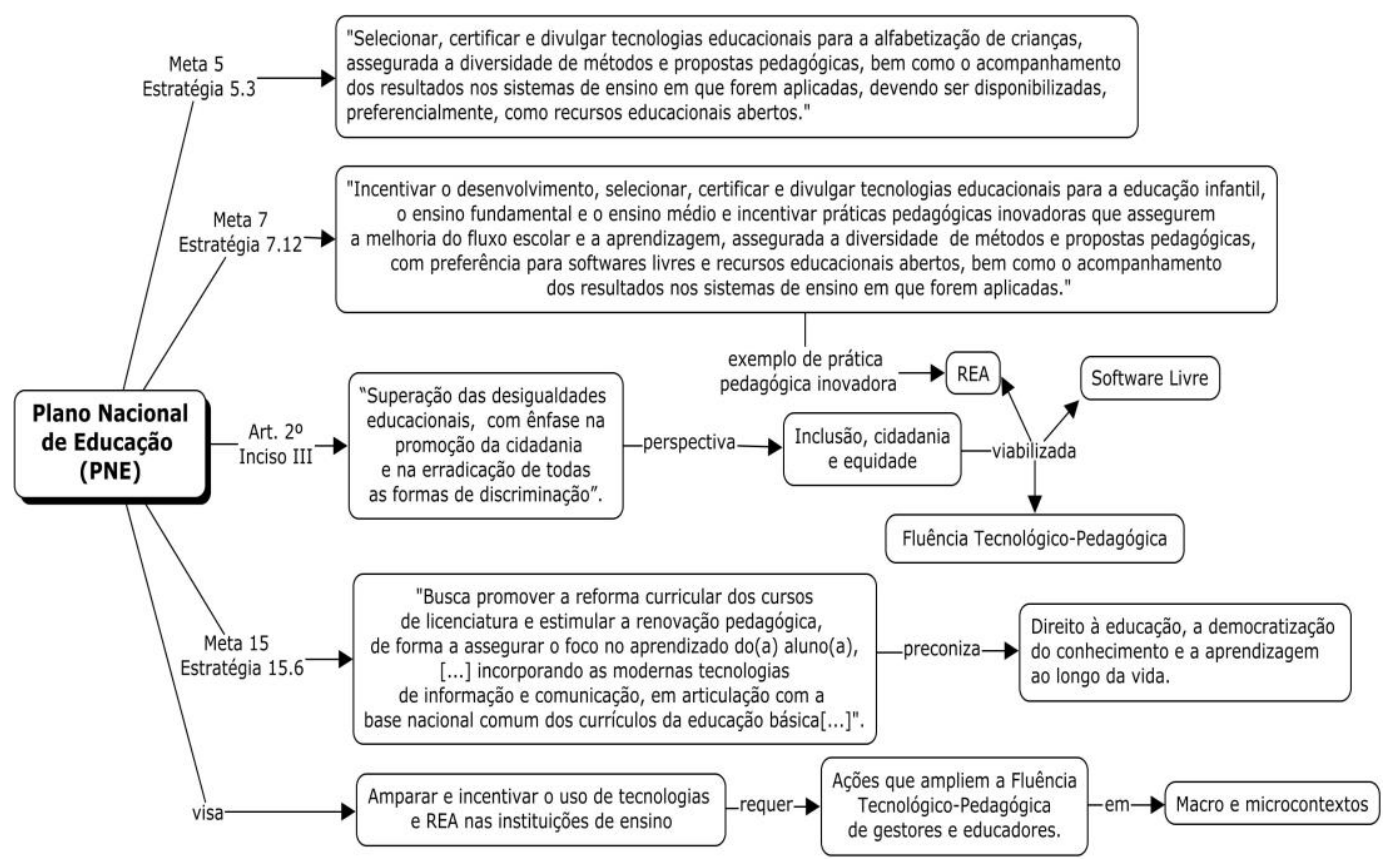

Fonte: Elaboração própria

Figura 3 - Dispositivos legais da BNCC

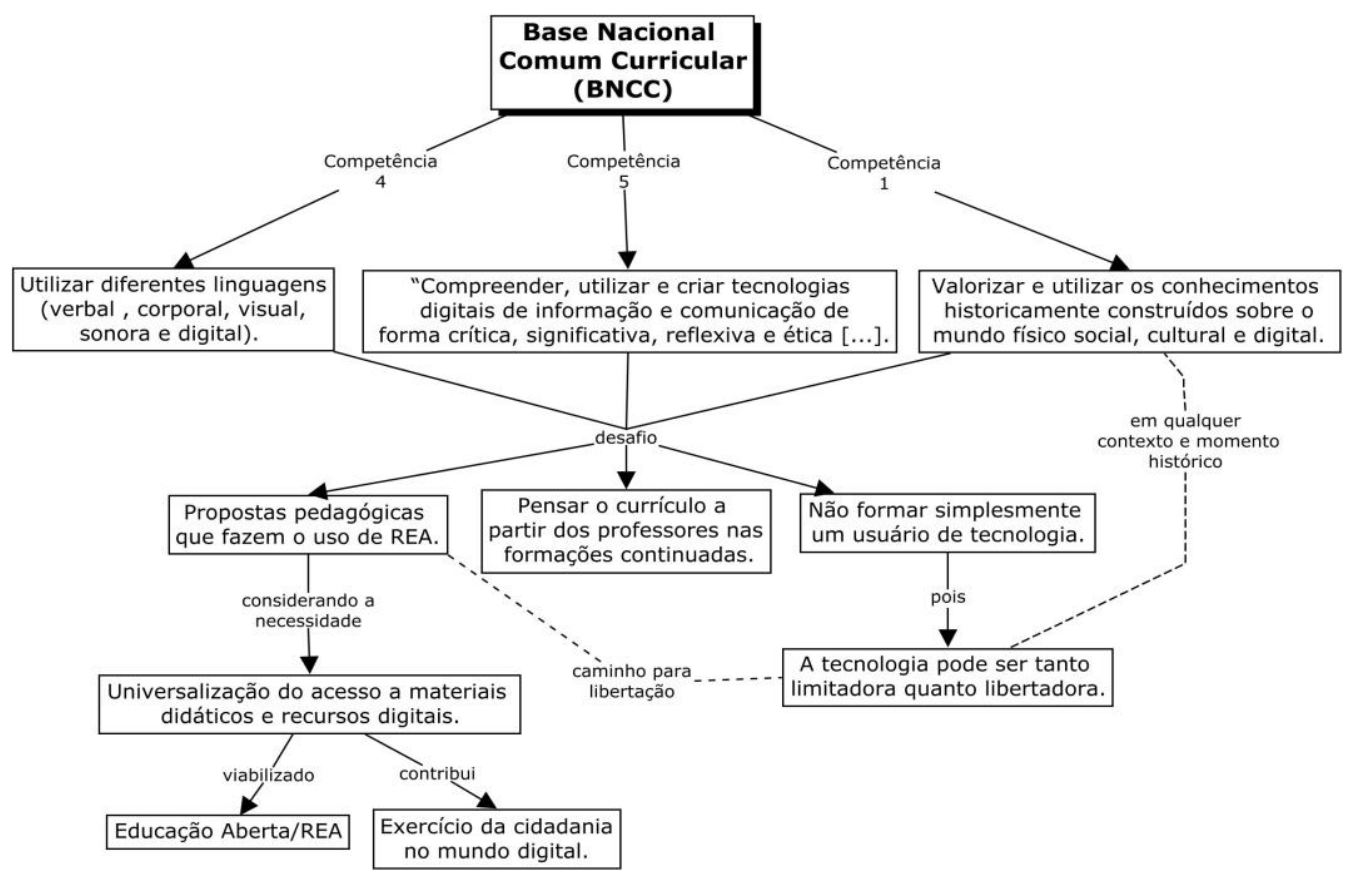

Fonte: Elaboração própria

Para evidenciar as bases textuais, foram selecionados as Recomendações sobre REA da UNESCO de 2019; o Plano Nacional de Educação (PNE) vigência 2014-2024; a Portaria n. 451, de 16 de maio de 2018; e a Resolução CNE/CP, n. 1 de 27 de outubro de 2020, que 
estabelece Diretrizes Curriculares Nacionais para Formação Continuada de Professores da Educação Básica e a Base Nacional Comum Curricular (BNCC).

A Resolução CNE/CP n. 01, que trata da formação continuada de professores, e mesmo o PNE, deixam transparente que as tecnologias são entendidas como arsenal instrumental sem que estejam atreladas a um arcabouço epistemológico, tal como têm sido desdobrados os princípios basilares da Fluência Tecnológico-Pedagógica (FTP). Evidentemente, no esforço sistemático e criativo explicitado nas redes temáticas foi possível tensionar confluências dos dispositivos legais em relação aos princípios do direito universal à educação, da democratização do conhecimento, aprendizagem ao longo da vida, inclusão, cidadania, equidade etc. Essas confluências não são inexistentes, todavia, como marcos fundantes de uma política pública com ética democrática ainda carecem de coesão e coerência. Ao primeiro filtro é nítido que as terminologias, as nomenclaturas e as referências conceituais são díspares entre si. É evidente que os dispositivos de documentos como a Portaria n. 451 e a BNCC destinam lugar procedimental para as tecnologias, já que a centralidade é a distribuição de recursos e a mecânica curricular reformista.

Com base nas sínteses evidenciadas nas Figuras 1, 2 e 3, as proposições conclusivas são sistematizadas nas células da MTA correspondentes às questões da MDP. Trata-se de criar sistemas teóricos passíveis de compreensão e dimensionamento que extrapolam os casos locais marcados pelas particularidades dos microcontextos. Desse modo, é possível construir referenciais analíticos legítimos e multimodais.

Quadro 2 - Proposições Conceituais da Matriz Temático-Analítica (MTA)

\begin{tabular}{|c|c|c|c|c|}
\hline & 1 -Professores & 2 - Estudantes & 3- Temática & 4- Contexto \\
\hline $\begin{array}{l}\text { D } \\
- \\
\text { Contexto }\end{array}$ & $\begin{array}{l}\text { D1) As políticas } \\
\text { públicas incentivam } \\
\text { reformas } \\
\text { curriculares } \\
\text { assentadas na } \\
\text { integração de } \\
\text { tecnologias } \\
\text { educacionais, REA e } \\
\text { software livre com } \\
\text { propósitos } \\
\text { ambiciosos de } \\
\text { alfabetização, } \\
\text { superação de } \\
\text { desigualdades e } \\
\text { promoção da } \\
\text { cidadania. No } \\
\text { entanto, não estão } \\
\text { acopladas à } \\
\text { dispositivos que }\end{array}$ & $\begin{array}{l}\text { D2) As políticas } \\
\text { públicas, } \\
\text { materializadas na } \\
\text { legislação vigente, } \\
\text { estabelecem metas, } \\
\text { diretrizes e } \\
\text { competências que } \\
\text { tangenciam as } \\
\text { tecnologias, software } \\
\text { livre e REA tanto para } \\
\text { Educação Básica } \\
\text { quanto Educação } \\
\text { Superior sendo } \\
\text { textualmente centradas } \\
\text { no provimento de } \\
\text { recursos digitais e } \\
\text { inconsistentes em } \\
\text { termos de equidade, } \\
\text { acesso, permanência e }\end{array}$ & $\begin{array}{l}\text { D3) As políticas } \\
\text { públicas nacionais } \\
\text { são improvidentes } \\
\text { em relação ao } \\
\text { fomento da } \\
\text { formação inicial e } \\
\text { continuada de } \\
\text { professores, basilar } \\
\text { na inovação } \\
\text { didático- } \\
\text { metodológica e } \\
\text { curricular o que } \\
\text { respalda discursos } \\
\text { negacionistas e } \\
\text { assertivas tecnicistas } \\
\text { em relação a práticas } \\
\text { abertas mediadas por } \\
\text { tecnologias, } \\
\text { software livre e }\end{array}$ & $\begin{array}{l}\text { D4) O caráter esparso } \\
\text { das diretrizes para } \\
\text { integração de } \\
\text { tecnologias, software } \\
\text { livre e REA na } \\
\text { educação pública } \\
\text { brasileira evidencia } \\
\text { que a prática das cinco } \\
\text { liberdades ainda é } \\
\text { incipiente nos } \\
\text { microcontextos da } \\
\text { Educação Básica e da } \\
\text { Educação Superior } \\
\text { gerando parcimônia } \\
\text { diante dos desafios } \\
\text { universais do direito à } \\
\text { educação, } \\
\text { democratização do } \\
\text { conhecimento e }\end{array}$ \\
\hline
\end{tabular}




\begin{tabular}{|l|l|l|l|l|}
\hline $\begin{array}{l}\text { proporcionem } \\
\text { efetivo } \\
\text { aprimoramento da } \\
\text { Fluência } \\
\text { Tecnológico- } \\
\text { Pedagógica (FTP) } \\
\text { como } \\
\text { desenvolvimento e } \\
\text { valorização dos } \\
\text { profissionais da } \\
\text { educação } \\
\text { englobando } \\
\text { docência, pesquisa, } \\
\text { extensão e gestão. }\end{array}$ & & REA. & $\begin{array}{l}\text { aprendizagem ao } \\
\text { longo da vida. }\end{array}$ \\
\hline
\end{tabular}

Fonte: Elaboração própria

Os resultados ressaltam a pluralidade de percepções, traduções e (re)interpretações locais das políticas relacionadas às tecnologias educacionais e Recursos Educacionais Abertos (REA). Não causa estranheza, portanto, que as práticas discursivas demarquem variadas tipologias ingênuas em curvaturas deterministas que vão desde a negacionista até a futurologista. Embora todos os documentos da legislação vigente selecionados recorram às tecnologias, ao software livre, licenças abertas e aos REA como fortalezas, é notório o caráter descompromissado em relação à formação, desenvolvimento e valorização dos profissionais da educação.

\section{Considerações finais}

Os princípios universais como o direito à educação, democratização do conhecimento e aprendizagem ao longo da vida localizam-se no centro de um debate polissêmico. As variáveis são amplas, uma vez que são baseadas num acúmulo histórico de demandas, expectativas e forças democráticas ora mais neoliberais, populistas e/ou mais neoconservadoras. Nessa direção, ampliar e fortalecer a Fluência Tecnológico-Pedagógica (FTP) em torno dos Recursos Educacionais Abertos (REA) e demais desdobramentos contemporâneos é um caminho necessário para corrigir as distorções de acesso, permanência e conclusão dos estudos com sucesso.

Ampliar a produção, a disponibilização, o remix, a readaptação e a circulação de REA situa-se no quadro da educação como direito social universal, visando democratização do acesso como modo de operar a justiça social. Nesse sentido, as políticas públicas, numa esfera democrática que se ocupa com o bem-estar e pressupõe a igualdade, precisam fomentar a Fluência Tecnológico-Pedagógica (FTP) em torno das tecnologias educacionais em rede e dos REA. É dessa forma que será possível mobilizar o capital cultural de todas as pessoas 
envolvidas na defesa do direito à educação, democratização do conhecimento e aprendizagem ao longo da vida.

A construção teórica em torno das tecnologias educacionais em rede e dos REA precisa ser realizada por todos: especialistas, pesquisadores, gestores, professores e estudantes, tanto da Educação Superior quanto da Educação Básica. Para isso, é basilar compreender que: a) os REA estão inseridos num contexto real em que pesam as políticas públicas materializadas na legislação vigente; b) transposições consolidadas dos REA nos microcontextos implicam existência de diretrizes políticas e ações institucionais seriamente compromissadas com a ética da inclusão, equidade, democratização do conhecimento; c) são necessários canais de divulgação e participação da sociedade civil durante os processos de tessitura da legislação e, inclusive, para avaliações durante a implementação, o que pode viabilizar diálogos produtivos e soluções mais confiáveis e legítimas.

AGRADECIMENTOS: Fundação de Amparo à Pesquisa do Estado do Rio Grande do Sul (FAPERGS) - Programa Pesquisador Gaúcho - PqG Edital 02/2017.

\section{REFERÊNCIAS}

APPLE, M. "Endireitar" a educação: as escolas e a nova aliança conservadora. Currículo sem Fronteiras, v. 2, n. 1, p. 55-78, jan./jun. 2002.

GUERRA, D.; FIGUEIREDO, I. M. Z.; ZANARDINI, I. M. S. Políticas sociais e o direito à educação. Revista Ibero-Americana de Estudos em Educação, Araraquara, v. 15, n. esp. 3, p. 2188-2203, nov., 2020. e-ISSN: 1982-5587. DOI:

https://doi.org/10.21723/riaee.v15iesp3.14425

JACQUES, J. S.; MALLMANN, E. M.; BAGETTI, S. Recursos Educacionais Abertos e para Mobilização do Conhecimento em Educação de Forma Crítica. ETD-Educação Temática Digital, Campinas, v. 21, n. 4, p. 1043-1059, out./dez. 2019. DOI:

https://doi.org/10.20396/etd.v21i4.8652434

MAINARDES, J. Abordagem do ciclo de políticas: uma contribuição para análise de políticas educacionais. Educ. Soc., Campinas, v. 27, n. 94, p. 47-69, jan./abr. 2006. DOI: https://doi.org/10.1590/S0101-73302006000100003

MALLMANN, E. M. Pesquisa-ação educacional: preocupação temática, análise e interpretação crítico-reflexiva. Cad. Pesqui., São Paulo, v. 45, n. 155, p. 76-98, mar. 2015. DOI: https://doi.org/10.1590/198053143088

MALLMANN, E. M.; QUINTAS-MENDES, A. M. Fluência Tecnológico-Pedagógica e a Prática das Cinco Liberdades com Recursos Educacionais Abertos. In: FERNANDES, T.; 
MACIEL, C.; SANTOS, E. (Org.) Educação a distância: multiletramentos e linguagens multimodais. Cuiabá: EdUFMT, 2020. v. 2.

SANTANA, A. C. M.; CARDOSO, M. C.; SILVA, T. A. A. A Formação de professores e a Teoria Crítica: entre o mercado e a emancipação humana. Revista Ibero-Americana de Estudos em Educação, Araraquara, v. 14, n. esp. 4, p. 2003-2016, dez. 2019. e-ISSN: 19825587. DOI: https://doi.org/10.21723/riaee.v14iesp.4.12924

UNESCO. Declaração REA de Paris em 2012. Congresso mundial sobre Recursos Educacionais Abertos (REA) de 2012. Paris: UNESCO, 2012. Disponível em: http://www.rea.net.br/site/declaracao-rea-de-paris-2012/. Acesso em: 19 nov. 2020.

VIERA PINTO, Á. O conceito de tecnologia. Rio de Janeiro: Contraponto, 2005. v. 1.

WENCZENOVICZ, T. J. Ensino a distância, dificuldades presenciais: perspectivas em tempos de COVID-19. Revista Ibero-Americana de Estudos em Educação, Araraquara, v. 15, n. 4, p. 1750-1768, out./dez. 2020. e-ISSN: 1982-5587. DOI:

https://doi.org/10.21723/riaee.v15i4.13761

WILEY, D. OpenContent.org. 2014a Disponível em: http://www.opencontent.org/definition/. Acesso em: 19 nov. 2020.

WILEY, D. The Access Compromise and the 5th R. Iterating toward openness. 2014. Disponível em: http://opencontent.org/blog/archives/3221. Acesso em: 19 nov. 2020.

WILEY, D. The Instructional Use of Learning Objects: Online Version. USA: Association for Educational Communications and Technology, 2000. Disponível em: http://reusability.org/read/chapters/wiley.doc. Acesso em: 19 nov. 2020.

\section{Como referenciar este artigo}

MALLMANN, E. M.; SCHNEIDER, D. R. Políticas públicas, tecnologias educacionais e Recursos Educacionais Abertos (REA). Revista Ibero-Americana de Estudos em Educação, Araraquara, v. 16, n. esp. 2, p. 1113-1130, maio 2021. e-ISSN: 1982-5587. DOI: https://doi.org/10.21723/riaee.v16iesp2.15118

Submissão em: $15 / 12 / 2020$

Revisões requeridas em: 28/01/2021

Aprovado em: 03/03/2021

Publicado em: 01/05/2021 